\title{
A study and analysis of the economic burden of hypertensive cerebral hemorrhage.
}

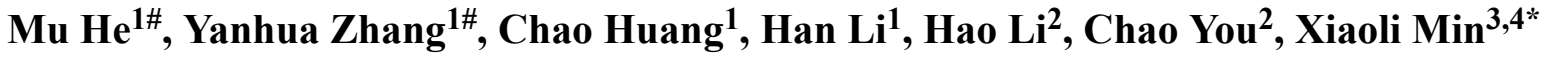 \\ ${ }^{1}$ Province Forestry Center Hospital of Sichuan University, Chengdu, Sichuan, China \\ ${ }^{2}$ West China Medical Center of Sichuan University, Chengdu, Sichuan, China \\ ${ }^{3}$ Second Affiliated Hospital of Kunming Medical University, Yunnan, China \\ ${ }^{4}$ Yunnan University of Traditional Chinese Medicine, Kunming, Yunnan, China \\ ${ }^{\#}$ Contributed equally
}

\begin{abstract}
Objective: The aim of this article was to comprehensively examine the current and project burden of hypertensive cerebral hemorrhage in southwest region of China.

Methods: Summary and analysis of the data of the patients from the Sichuan Province Forestry Centre Hospital, the Second Affiliated Hospital of Kunming Medical University, the West China Hospital of Sichuan University, the Yunnan University of Traditional Chinese Medicine, 2010-2017.

Results: The medical cost of patients with hypertensive intracerebral hemorrhage was estimated at RMB 12196.00 (USD 1896.73) per person per year. The total costs of intracerebral hemorrhage were higher in surgery group (RMB 36632.50 or USD 5697.12) than non-surgery group (RMB 6333.00 or USD 984.91). The direct medical costs of surgery group were RMB 32534.00 (USD 5059.72), in contrast with the costs of non-surgery treatments, which were RMB 3781.75 (USD 588.14).

Conclusion: In this paper, all 1640 cases of hypertensive intracerebral hemorrhage research data and follow-up data, we learned that the economic burden of hypertensive cerebral hemorrhage is heavy for the Chinese people and the nation.
\end{abstract}

Keywords: Hypertension, Cerebral hemorrhage, Economic burden, Outcome assessment.

Accepted on March 30, 2019

\section{Introduction}

Intracerebral hemorrhage (ICH), for $9 \%$ to $27 \%$ of all strokes worldwide [1], is often acute, and in recent year surgery and drug treatments in intracerebral hemorrhage are taken so that such diseases are treatable. In the meanwhile, these treatments also increase the financial burden of intracerebral hemorrhage which has increased between 1990 and 2010 by 47\% [2,3]. The incidence, mortality, disability adjusted life years (DALYs) lost, and mortality-to-incidence ratio are different between high-income countries and middle- and low-income countries [2]. Except for traumatic ICHaneurysm/subarachnoid or intracranial vascular malformations hemorrhage, hypertension and amyloid angiopathy are the most common ICH etiology, however, coagulopathy, vascular anomalies, tumors, and drugs also play a significant role especially in China [4,5]. But there are many issues, such as the relationship between choices of surgical treatment for intracerebral hemorrhage and health care coststhe impact of the economic burden in postoperative complications for patients and their families. At present such relatively economic researches on hypertension related intracerebral hemorrhage are few and circumscribed [3,5-8]. We hope that the evaluation and research of economic burden of intracerebral hemorrhage and allocation of health care resources achieve a reasonable close in China or Asian. And we believe that the economic burden of intracerebral hemorrhage exploration, either directly or indirectly, for our treatment of intracerebral hemorrhage treatment, after treatment, medical integration, care, disease prevention and others show medical measures evidence and make us better improve health, strengthen the construction of primary health care and widespread popularity of the prevention and treatment of intracerebral hemorrhage.

\section{Method}

Patients with a primary ICD-10 diagnosis of ICH, excluding traumatic ICH tumor apoplexy, aneurysm/subarachnoid or intracranial vascular malformations hemorrhage [9], treated at the Sichuan Province Forestry Center Hospital, the Second Affiliated Hospital of Kunming Medical University, the West China Hospital of Sichuan University and the Yunnan 
University of Traditional Chinese Medicine 2010-2017 were subjects of the study.

The questionnaire contained two main parts [10-12]. The first part included patient characteristics, such as sociodemographic details, information on concurrent conditions, and the main clinical features of the disease (headache, vomiting, paralysis, unconsciousness, etc.). After admission to the Glasgow Coma Scale (Glasgow Coma Scale, GCS) to assess patients generally Awareness and record age, sex, blood pressure, hospitalization and number of days of basic information; while CT data recorded on the basis of bleeding location, amount of bleeding, midline shift the incidence side, whether breaking into the ventricle, whether hydrocephalus and other information. The second portion comprises the use of resources and cost, consisting of two parts: I: direct assessment hospital, consultation, surgery, blood pressure control, the cost of inspection. II: utilization including nutritional support and hospitalization costs of environmental assessment resource and some special equipment.

Direct costs of illness were grouped as those related to diagnosis (CT imaging, and so on) and treatment (for example, cost of medicines or surgeries) or recurring (for example, cost of medicines, medical consultations and hospitalization). Unit costs were derived from the Sichuan province public health administrations tariff (annual listing of all licensed drugs in China and their prices), and the local fees for home care and home health service provided by the local authority. Most of the patients come with two attendants to the hospital. The initial valuation of cost items was in Chinese currency, renminbi (RMB). For reference, the exchange rate was USD $1=\mathrm{RMB} 6.43$ in average.

We used SPSS 13.0 (Statistical Package for the Social Sciences) and Microsoft Access and Excel (Microsoft, 2003; Redmond, WA, U.S.A.) for data management and analysis. However, the median cost could be zero for highly skewed data. Therefore, mean values and ranges are given instead. Kruskal-Wallis analysis of variance was used and two-tailed $\mathrm{P}$ values were presented, and values below 0.05 were considered to indicate statistical significance.

\section{Results}

\section{Characteristics of patients}

There were 1640 patients in total. The male patients with 1085 cases, accounting for $66.16 \%$, female 555 cases, accounting for $33.84 \%$. Male to female ratio is $1.95: 1.2$. Their mean age 61.00 \pm 0.40 years (range 20 to 95 years). All patients were permanent residents of Sichuan and Yunnan province, and 1090 cases were from urban, the others inhabited in rural. The demographic details were shown in Table 1.

\section{Clinic features of patients about surgery or non- surgery treatment}

There were 1430 cases of supratentorial, infratentorial in 210 cases. Major bleeding in the basal ganglia area were 965 cases, accounting for $58.5 \%$. Others were the thalamus $(12.80 \%)$, brain lobes $(10.37 \%)$, brain stem $(8.85 \%)$, ventricles $(5.18 \%)$, cerebellum (3.96\%). Hematoma volume averaged $45.00 \pm$ $20.60 \mathrm{ml}$ (range 5 to $80 \mathrm{ml}$ ). GCS on admission with an average score of $11.00 \pm 1.00$ points (range 3 to 15 ). There were 590 patients who had surgical indications. Only 450 cases chose surgery treatment and the others chose non-surgery treatment. 805 patients knew hypertension history by theirselves while all patients were tested out higher blood pressure in hospital. The demographic details were shown in Table 2.

Table 1. Demographic characteristics of patients for intracerebral hemorrhage from 2010 to 2017.

\begin{tabular}{|c|c|c|}
\hline Case & Number of patients $(\mathrm{N}=1640)$ & Percent of patients (\%) \\
\hline \multicolumn{3}{|l|}{ Sex } \\
\hline Male & 1085 & 66.16 \\
\hline Female & 555 & 33.84 \\
\hline \multicolumn{3}{|l|}{ Age (years) } \\
\hline$<50$ & 370 & 22.57 \\
\hline $50-60$ & 375 & 22.87 \\
\hline $60-70$ & 470 & 28.66 \\
\hline $70-80$ & 325 & 19.81 \\
\hline$\geq 80$ & 100 & 6.09 \\
\hline \multicolumn{3}{|l|}{ Payment } \\
\hline Medicare & 215 & 13.11 \\
\hline Private insurance & 180 & 10.98 \\
\hline Self-pay & 1245 & 75.91 \\
\hline \multicolumn{3}{|l|}{ Resident location } \\
\hline Urban & 1090 & 66.46 \\
\hline Rural & 550 & 33.54 \\
\hline
\end{tabular}

Table 2. Clinic features of patients for intracerebral hemorrhage from 2010 to 2017.

\begin{tabular}{|c|c|c|c|c|c|c|}
\hline Case & $\begin{array}{l}\text { Number of patients } \\
(\mathrm{N}=1640)\end{array}$ & $\begin{array}{l}\text { Percent of } \\
\text { patients }(\%)\end{array}$ & $\begin{array}{l}\text { Surgery treatment number of } \\
\text { patients }(N=450)\end{array}$ & $\begin{array}{l}\text { Percent of } \\
\text { patients (\%) }\end{array}$ & $\begin{array}{l}\text { Non-surgery treatment number of } \\
\text { patients }(\mathrm{N}=1190)\end{array}$ & $\begin{array}{l}\text { Percent of } \\
\text { patients (\%) }\end{array}$ \\
\hline \multicolumn{7}{|c|}{ atoma } \\
\hline
\end{tabular}




\begin{tabular}{|c|c|c|c|c|c|c|}
\hline $\begin{array}{l}\text { Basal ganglia } \\
\text { region }\end{array}$ & 965 & 58.84 & 51 & 56.67 & 142 & 59.66 \\
\hline Thalamus & 210 & 12.8 & 9 & 10 & 33 & 13.86 \\
\hline Encephalocoele & 85 & 5.18 & 5 & 5.56 & 12 & 5.04 \\
\hline Cerebellum & 65 & 3.96 & 6 & 6.67 & 7 & 2.94 \\
\hline Lobe & 170 & 10.37 & 16 & 17.77 & 18 & 7.56 \\
\hline Brain stem & 145 & 8.85 & 3 & 3.33 & 26 & 10.94 \\
\hline \multicolumn{7}{|l|}{ GCS } \\
\hline 15 & 65 & 3.96 & 0 & 0 & 13 & 5.46 \\
\hline $13-14$ & 705 & 42.99 & 34 & 37.78 & 107 & 44.96 \\
\hline $9-12$ & 455 & 27.74 & 39 & 43.33 & 52 & 21.85 \\
\hline $3-8$ & 415 & 25.31 & 17 & 18.89 & 66 & 27.73 \\
\hline \multicolumn{7}{|c|}{ Volume of hematoma (ml) } \\
\hline$<10$ & 170 & 10.37 & 3 & 3.33 & 31 & 13.02 \\
\hline $10-20$ & 560 & 34.15 & 10 & 11.11 & 102 & 42.86 \\
\hline $20-30$ & 450 & 27.44 & 10 & 11.11 & 80 & 33.61 \\
\hline $30-40$ & 260 & 15.85 & 35 & 38.89 & 17 & 7.14 \\
\hline 40 & 200 & 12.19 & 32 & 35.56 & 8 & 3.37 \\
\hline \multicolumn{7}{|l|}{ Past history } \\
\hline Hypertension & 805 & 49.09 & - & - & - & - \\
\hline $\begin{array}{l}\text { Diabetes } \\
\text { mellitus }\end{array}$ & 170 & 10.37 & - & - & - & - \\
\hline $\begin{array}{l}\text { Coagulation } \\
\text { deficiency }\end{array}$ & 15 & 0.91 & - & - & - & - \\
\hline Renal disease & 30 & 1.83 & - & - & - & - \\
\hline $\begin{array}{l}\text { Chronic lung } \\
\text { disease }\end{array}$ & 100 & 6.1 & - & - & - & - \\
\hline $\begin{array}{l}\text { Congestive } \\
\text { heart failure }\end{array}$ & 25 & 1.52 & - & - & - & - \\
\hline
\end{tabular}

\section{Prognosis of patients for intracerebral hemorrhage}

The average length of hospitalization was $6.30 \pm 1.30$ days. The longest hospitalization period is 49 days, and the shortest hospitalization period is 1 day. Among them, there were 190 deaths, accounting for $11.58 \%$. There were 235 cases of automatic discharge, accounting for $14.33 \%$. The average of GOS score was $3.11 \pm 1.42$ points in one month, and the average of MRS score was $3.10 \pm 2.00$ points. The most common complication is lung infection with 565 cases accounting for $11.58 \%$. The demographic details were shown in Table 3.

Table 3. Outcomes of patients for intracerebral hemorrhage from 2010 to 2017.

$\begin{array}{llll}\text { Case } & \begin{array}{l}\text { Number } \\ (\mathrm{N}=1640)\end{array}\end{array}$ of patients $\begin{aligned} & \text { Percent of patients } \\ & (\%)\end{aligned}$

\begin{tabular}{lll}
\hline Hospital stay (day) & & \\
\hline$<7$ & 270 & 16.46 \\
\hline $7-14$ & 675 & 41.16 \\
\hline $14-28$ & 400 & 24.39 \\
\hline$\geq 28$ & 295 & 17.99 \\
\hline GOS & & \\
\hline 1 & 190 & 11.58 \\
\hline 2 & 355 & 21.65 \\
\hline 3 & 380 & 23.17 \\
\hline 4 & 520 & 31.71 \\
\hline 5 & 195 & 11.89 \\
\hline MRS & & \\
\hline
\end{tabular}




\begin{tabular}{|c|c|c|}
\hline 6 & 190 & 11.58 \\
\hline 5 & 180 & 10.98 \\
\hline 4 & 235 & 14.33 \\
\hline 3 & 355 & 21.65 \\
\hline 2 & 420 & 25.61 \\
\hline 1 & 205 & 12.5 \\
\hline 0 & 55 & 3.35 \\
\hline \multicolumn{3}{|l|}{ Complication } \\
\hline Lung infection & 565 & - \\
\hline Deep vein thrombosis & 45 & - \\
\hline Pressure sore & 50 & - \\
\hline Electrolyte disorder & 375 & - \\
\hline $\begin{array}{l}\text { Congestive heart } \\
\text { failure }\end{array}$ & 10 & - \\
\hline Renal disease & 5 & - \\
\hline
\end{tabular}

\begin{tabular}{lll}
\hline Others & 45 & - \\
\hline
\end{tabular}

\section{Cost of intracerebral haemorrhage}

The total costs of intracerebral hemorrhage were higher in surgery group (RMB 36632.50 or USD 5697.12) than nonsurgery group (RMB 6333.00 or USD 984.91). The direct medical costs of surgery group were RMB 32534.00 (USD 5059.72), in contrast with the costs of non-surgery treatments, which were RMB 3781.75 (USD 588.14). It can be seen in Table 4 that the pattern of resource use in the categories is not uniform. In patients with intracerebral hemorrhage, the main cost was for surgery cost in surgery group which including surgery fees, anesthesia fee, material fee and so on. Meanwhile in the non-surgery group the highest cost was for drugs.

A few of the patients $(24.09 \%)$ had some kind of medical insurance, which could cover a part of medical costs. However, only $13.11 \%$ patients utilized the medical insurance to pay for the cost when leaving the hospital directly, whereas $75.91 \%$ patients paid the whole costs by themselves, including $10.98 \%$ of them could cover a part of the costs after leaving hospital by local government or insurance company.

Table 4. Median intracerebral hemorrhage-related cost (RMB) per patient.

\begin{tabular}{|c|c|c|c|}
\hline Cost & Surgery treatment of patients $(\mathrm{N}=450)$ & Non-surgery treatment of patients $(\mathrm{N}=1190)$ & Total cost $(\mathrm{N}=1640)$ \\
\hline Direct medical cost & $32534.00(789.00-100660.00)$ & $3781.75(23.00-67104.00)$ & $7966.0(23.00-100660.00)$ \\
\hline Inpatient basic cost & $4510.00(539.00-17520.00)$ & $1004.40(66.00-21456.00)$ & $2456.00(66.00-21456.00)$ \\
\hline Outpatient basic cost & $100.00(0.00-1500.00)$ & $92.00(0.0-1550.0)$ & $99.00(0.0-1550.0)$ \\
\hline Surgery cost & $14495.00(3210.00-24794.00)$ & - & $14495.00(3210.00-24794.00)$ \\
\hline Drug cost & $11925.00(200.00-81560.00)$ & $2255.25(100.00-52000.00)$ & $4349.00(100.00-81560.00)$ \\
\hline Examination cost & $1218.00(50.00-5000.00)$ & $509.00(250.00-6368.00)$ & $784.00(50.00-6368.00)$ \\
\hline Direct non-medical cost & $920.00(100.00-27000.00)$ & $78.00(10.00-4840.00)$ & $200.00(10.00-27000.00)$ \\
\hline Home care & $270.00(100.0-8000.00)$ & $50.00(0.00-3340.00)$ & $100.00(0.00-8000.00)$ \\
\hline Preventive care foods & $150.00(0.00-18000.00)$ & $120.00(0.00-1000.00)$ & $144.00(0.00-18000.00)$ \\
\hline Special equipments & $450.00(0.00-1000.00)$ & $625.50(0.00-1500.00)$ & $500.00(0.00-1500.00)$ \\
\hline Overall median total cost & 36632.50 (809.00-170019.00) & $6333.00(63.0-903084.0)$ & $12196.00(63.0-903084.0)$ \\
\hline
\end{tabular}

\section{Analysis of feature between surgery group and non- surgery group}

Based on these data (Table 5), the distribution of female in the surgical group was more than that in non-surgery group but it was not statistically significant $(\mathrm{P}=1.42>0.05)$. Patients in the surgical group were significantly younger than those in the conservative treatment group which had statistical significance $(\mathrm{P}=0.015<0.05)$. The GCS score of the conservative treatment group (mean 11.2 points) was higher than the GCS score of the surgery group (mean 9.9 points), which was statistically significant $(\mathrm{P}=0.04<0.05)$. The situation of patients in the conservative treatment group was better than that in the surgical treatment group before receiving the treatment. The prognosis of non-surgery group was a little better than surgery group, but it was not statistically significant (GOS, MRS, $\mathrm{P}=0.061,0.072>0.05)$. The total costs, direct medical expenses, and indirect medical expenses of the surgical treatment group were significantly higher than those of the non-surgical treatment group, which were statistically significant $(\mathrm{P}=0.000<0.05)$.

Table 5. Contradistinction of characteristics and costs between surgery group and non-surgery group. 


\begin{tabular}{llll}
\hline Case & Surgery treatment of patients $(\mathbf{N}=\mathbf{4 5 0})$ & Non-surgery treatment of patients $(\mathbf{N}=\mathbf{1 1 9 0})$ & $\mathbf{p}$ \\
\hline Sex $(\mathrm{F} \%)$ & 42.22 & 30.67 & 1.42 \\
\hline Age & $58.80 \pm 3.50$ & $61.70 \pm 2.50$ & $0.015^{*}$ \\
\hline GCS & $9.90 \pm 1.20$ & $11.20 \pm 2.10$ & $0.040^{*}$ \\
\hline GOS & $2.62 \pm 0.80$ & $3.18 \pm 1.10$ & 0.061 \\
\hline MRS & $3.51 \pm 1.10$ & $2.79 \pm 0.50$ & 0.072 \\
\hline Overall median total cost & $36632.50(809.00-170019.00)$ & $6333.00(63.0-903084.0)$ & $0.000^{\#}$ \\
\hline Direct medical cost & $32534.00(789.00-100660.00)$ & $3781.75(23.00-67104.00)$ & $0.000^{\#}$ \\
\hline Direct non-medical cost & $920.00(100.00-27000.00)$ & $78.00(10.00-4840.00)$ & $0.000^{\#}$ \\
\hline
\end{tabular}

All data were expressed as mean \pm standard deviation and were analyzed by One-Way ANOVA $\left({ }^{*} p<0.05,{ }^{* *} p<0.01,{ }^{\#} p<0.005\right)$

\section{Discussion}

The assessment of the costs of hypertensive intracerebral hemorrhage was increasingly required by government agencies to achieve the best resource allocation and to evaluate the costbenefit ratio and cost-effectiveness of diagnostic treatment. It currently lacked the cost of hypertensive cerebral hemorrhage research in Chinese, even in the global. Therefore, whether the diagnosis and treatment of hypertensive intracerebral hemorrhage or not in the individual, family, medical services, social class, and other aspects of the economic burden were caused by the need for further study. In addition, the cost differs depending on the condition, the treatment method, and the effect of the drug. Understanding the total cost of the disease had important implications for understanding the cost of patients with different medical conditions.

From the general data of patients in this study, patients with hypertensive intracerebral hemorrhage had slightly more men than women. The age of onset was still mainly in the elderly. The bleeding site was mainly found in the basal ganglia, which was consistent with previous literature reports $[1,13,14]$. Patients in the surgical treatment group had relatively poor physical health conditions at the time of admission compared with those in the conservative treatment group, which was statistically significant. This was also one of the factors that influenced the prognosis of patients. In addition, there was no statistically significant difference in the outcome of the treatment of patients with or without surgical treatment. However, these factors had an impact on the patient's medical costs.

The medical cost of patients with hypertensive intracerebral hemorrhage was estimated at RMB 12196.00 (USD 1896.73) per person per year. Some researches which had been done in China had pointed out that hypertensive intracerebral hemorrhage accounted for $14-24 \%$ of stroke, and the annual incidence of stroke in China was 130/100 000 [15-17]. Therefore, there were at least 500,000 patients with hypertensive intracerebral hemorrhage in China every year. According to this data, the annual costs of hypertensive cerebral hemorrhage in China was RMB 6.1 billion (USD 0.95 billion). In 2007, China's GNP was RMB 25,188.1 billion
(USD 3917.23 billion), with a per capita of RMB 17,227 (USD 2679.16). In 2010, Sichuan's per capita annual income was RMB 15,461 (USD 2404.51). Thus, the per capita cost of hypertensive intracerebral hemorrhage accounts for $70.8 \%$ of the national per capita GNP and accounted for $78.9 \%$ of Sichuan's per capita annual income. Annual costs accounted for $0.024 \%$ of GNP. The cost of stroke for the year 2002 was estimated to be as high as $\$ 49.4$ billion in the United States, while costs after hospital discharge were estimated to amount to 2.9 billion Euros in France [18-21,22]. Clearly, even a fraction of such amounts can cause enormous economic damage to low-income countries [19,23]. Therefore, hypertensive cerebral hemorrhage was a high-cost disease. However, for China and the entire country, more and more research was still needed to know the results.

At present, the main ways to treat hypertensive intracerebral hemorrhage were two ways about surgical treatment and conservative treatment. From this study, the cost of surgical treatment (RMB 36632.50 or USD 5697.12) is higher than the costs of conservative treatment (RMB 6333.00 or USD 984.91). The patient's condition on admission of the surgery group was severe. Surgically treated patients were prone to complications after surgery containing lung infection $(34.45 \%)$, electrolyte disorder $(22.87 \%)$ and so on, which increased patient's length of stay and the using of drugs. The above-mentioned absolutely increased the economic burden of the medicine. A study in Togo estimated direct cost per person of 936 Euros in only 17 days, about 170 times more than the average annual heath spend of a Togolese [23,24]. Subsidising and improving post-stroke care may help to reduce stroke case fatality rates and morbidity in Africa [21,24].

The actual cost of patients with hypertensive intracerebral hemorrhage might be underestimated. Several reasons: First, the data of later rehabilitation and outpatient follow-up of hypertensive intracerebral hemorrhage were not easy to collect. Because the patients returned to the local hospital, they would visit the local hospital, or no longer follow-up. Second, the help of family members such as spouses and children could not be counted because these were difficult to measure with monetary value. However, in China, because of economic and 
cultural factors, only a few families would employ nursing staff, which meaning that the patient needed help. Family members undertook most of the nursing tasks. This might be the reason why in the developed countries, social services accounted for more than $10 \%$, while in China only $2.4 \%$ $[25,26]$. Third, the expenses for travel on the roads of some emergency or transfer patients and car travel expenses for follow-up visits were not included [27-39].

In addition, our study found a contradiction between the coverage of insurance for hypertensive intracerebral hemorrhage patients and the rate of insurance use. First of all the patient's family members did not understand the insurance. Then the reimbursement procedure was complicated and some patients were unclear. At last this showed that hypertensive intracerebral hemorrhage was not only an economic burden but also a social and family burden for patients [40].

\section{Conclusion}

In this paper, all 1640 cases of hypertensive intracerebral hemorrhage research data and follow-up data, we learned that the economic burden of hypertensive cerebral hemorrhage is heavy for the Chinese people and the nation. The total cost and severity of the disease as well as surgery and drug therapy were significantly different responses to contact. In addition, the cost of new drugs and drug has a close relationship. Calculated through statistical conclusions: Hypertensive cerebral hemorrhage prognosis of patients with surgical group and non-surgical group is not statistically significant; and the patient's condition in the surgical group is much more serious than that of patients to non-surgical group with statistical significance. The cost of surgical group of patients with hypertensive cerebral hemorrhage in the total costs, direct medical costs, direct non-medical costs, indirect costs are higher than non-surgical group, and which are statistically significant. The cost of surgical group of patients with hypertensive cerebral hemorrhage in direct medical costs, operation costs, inspection costs, care costs are higher than non-surgical group, and which are statistically significant. Factors which affect postoperative are complications, age and previous history of such illness. The direct non-medical costs of surgical group of patients are higher than non-operated group, and which is statistically significant. The indirect costs of surgical group of patients are higher than that of nonsurgical group, in addition to loss of productivity was not statistically significant, others have statistical significance. For the men ( $<60$ years old), women ( $<55$ years) with symptomatic patients, there is evidence for surgeon and early surgical operation, its return to society, into greatly increased probability of social reproduction. Restore the productivity of its value is higher than the value of lost productivity.

\section{References}

1. Feigin VL, Lawes CM, Bennett DA, Barker-Collo SL, Parag V. Worldwide stroke incidence and early case fatality reported in 56 population-based studies: a systematic review. Lancet Neurol 2009;8:355-369.
2. Feigin VL, Forouzanfar MH, Krishnamurthi R Mensah GA, Connor M, Bennett DA, Moran AE, Sacco RL, Anderson L, Truelsen T, O'Donnell M, Venketasubramanian $\mathrm{N}$, Barker-Collo $\mathrm{S}$, Lawes CM, Wang W, Shinohara Y, Witt E, Ezzati M, Naghavi M, Murray C, Global Burden of Diseases, Injuries, and Risk Factors Study 2010 (GBD 2010) and the GBD Stroke Experts Group. Global and regional burden of stroke during 1990-2010: findings from the global burden of disease study 2010. Lancet 2014;383:245-254.

3. Steiner T, Al-Shahi Salman R, Beer R, Christensen H, Cordonnier C, Csiba L, Forsting M, Harnof S, Klijn CJ, Krieger D, Mendelow AD, Molina C, Montaner J, Overgaard K, Petersson J, Roine RO, Schmutzhard E, Schwerdtfeger K, Stapf C, Tatlisumak T, Thomas BM, Toni D, Unterberg A, Wagner M, European Stroke Organisation. European Stroke Organisation (ESO) guidelines for the management of spontaneous intracerebral hemorrhage. Int J Stroke 2014;9:840-855.

4. Fewel ME, Thompson BG Jr, Hoff JT. Spontaneous intracerebral hemorrhage: a review. Neurosurg Focus 2003;15:E1.

5. Patil CG, Alexander AL, Hayden Gephart MG, Lad SP, Arrigo RT, Boakye M. A population-based study of inpatient outcomes after operative management of nontraumatic intracerebral hemorrhage in the United States. World Neurosurg 2012; 8:640-645.

6. Gloede TD, Halbach SM, Thrift AG, Dewey HM, Pfaff H, Cadilhac DA. Long-Term Costs of Stroke Using 10-Year Longitudinal Data From the North East Melbourne Stroke Incidence Study. Stroke 2014;45:3389-3394.

7. Specogna AV, Patten SB, Turin TC, Hill MD. Cost of spontaneous intracerebral hemorrhage in Canada during 1 decade. Stroke 2014;45:284-286.

8. Chan CL, Ting HW, Huang HT. The incidence, hospital expenditure, and, 30 day and 1 year mortality rates of spontaneous intracerebral hemorrhage in Taiwan. J Clin Neurosci 2014;21:91-94.

9. Hill MD, Silver FL, Austin PC, Tu JV. Rate of stroke recurrence in patients with primary intracerebral hemorrhage. Stroke 2000;31:123-127.

10. Reed SD, Blough DK, Meyer K, Jarvik JG. Inpatient costs, length of stay, and mortality for cerebrovascular events in community hospitals. Neurology 2001;57:305-314.

11. Tveiten A, Ljøstad U, Mygland A, Thomassen L, Pripp $\mathrm{AH}$, Naess H. Intracerebral hemorrhage in southern Norway--a hospital-based incidence study. Eur Neurol 2012:67:240-245.

12. Douglas MA, Haerer AF. Long-term prognosis of hypertensive intracerebral hemorrhage. Stroke 1982;13:488-491.

13. Feigin VL. Stroke epidemiology in the developing world. Lancet 2005;365:2160-2161.

14. Norrving B, Kissela B. The global burden of stroke and need for a continuum of care. Neurology 2013;80:S5-12. 
15. Fayad PB, MD, Awad AI. Surgery for intracerebral hemorrhage. Neurology 1998;51:69-73.

16. Broderick J, Connolly S, Feldmann E, Hanley D, Kase C, Krieger D, Mayberg M, Morgenstern L, Ogilvy CS, Vespa P, Zuccarello M; American Heart Association/American Stroke Association Stroke Council; American Heart Association/American Stroke Association High Blood Pressure Research Council; Quality of Care and Outcomes in Research Interdisciplinary Working Group. Guidelines for the Management of Spontaneous Intracerebral Hemorrhage in Adults 2007 Update. Circulation 2007;116:391-413.

17. Qureshi AI, Tuhrim S, Broderick JP, Batjer HH, Hondo H, Hanley DF Spontaneous intracerebral hemorrhage. N Engl J Med 2001;344:1450-1460.

18. Connor MD, Thorogood M, Modi G, Warlow CP. The burden of stroke in sub-Saharan Africa. Am J Prev Med 2007;33:172-173.

19. Lemogoum D, Degaute JP, Bovet P. Stroke prevention, treatment, and rehabilitation in sub-saharan Africa. Am J Prev Med. 2005;29:95-101.

20. Feigin VL, McNaughton H, Dyall L. Burden of stroke in Maori and Pacific peoples of New Zealand. Int J Stroke 2007;2:208-210.

21. Owolabi MO, Akarolo-Anthony S, Akinyemi R, Arnett D, Gebregziabher M, Jenkins C, Tiwari H, Arulogun O, Akpalu A, Sarfo FS, Obiako R, Owolabi L, Sagoe K, Melikam S, Adeoye AM, Lackland D, Ovbiagele B, Members of the H3Africa Consortium.. The burden of stroke in Africa: a glance at the present and a glimpse into the future. Cardiovasc J Afr 2015;26:S27-38.

22. Yoneda Y, Okuda S, Hamada R, Toyota A, Gotoh J, Watanabe M, Okada Y, Ikeda K, Ibayashi S, Hasegawa Y. Hospital cost of ischemic stroke and intracerebral hemorrhage in Japanese stroke centers. Health Policy 2005;73:202-211.

23. Ortegon M, Lim S, Chisholm D, Mendis S. Cost effectiveness of strategies to combat cardiovascular disease, diabetes, and tobacco use in sub-Saharan Africa and South East Asia: mathematical modelling study. BMJ 2012;344:e607.

24. Kammersgaard LP, Jorgensen HS, Reith J, Nakayama H, Houth JG, Weber UJ, Pedersen PM, Olsen TS. Early infection and prognosis after acute stroke: the Copenhagen Stroke Study. J Stroke Cerebrovasc Dis 2001;10:217-221

25. He J, Whelton PK, Vu B, Klag MJ. Aspirin and the risk of hemorrhage stroke: a meta-analysis of randomized controlled trials. JAMA 1998;280:1930-1935.

26. Toyoda K, Yasaka M, Iwade K, Nagata K, Koretsune Y, Sakamoto T, Uchiyama S, Gotoh J, Nagao T, Yamamoto M, Takahashi JC, Minematsu K; Bleeding with Antithrombotic Therapy (BAT) Study Group. Bleeding with Antithrombotic Therapy Study Group Dual antithrombotic therapy increases severe bleeding events in patients with stroke and cardiovascular disease: a prospective, multicenter,

observational study. Stroke 2008;39:1740-1745.

27. Steiner T, Rosand J, Diringer M. Intracerebral hemorrhage associated with oral anticoagulant therapy: current practices and unresolved questions. Stroke 2006;37:256-262.

28. Rost NS, Smith EE, Chang Y, Snider RW, Chanderraj R, Schwab K, FitzMaurice E, Wendell L, Goldstein JN, Greenberg SM, Rosand J. Prediction of functional outcome in patients with primary intracerebral hemorrhage: the FUNC score. Stroke 2008;39:2304-2309.

29. Prabhakaran S, Gupta R, Ouyang B, John S, Temes RE, Mohammad Y, Lee VH, Bleck TP. Acute brain infarcts after spontaneous intracerebral hemorrhage: a diffusionweighted imaging study. Stroke 2010 41:89-94.

30. Morgenstern LB, Hemphill JC, III, Anderson C, Becker K, Broderick JP, Connolly ES, Jr, Greenberg SM, Huang JN, Macdonald RL, Messe SR, Pamela H. Mitchell, Selim M, Tamargo RF. Guidelines for the management of spontaneous intracerebral hemorrhage: a guideline for healthcare professionals from the American Heart Association/American Stroke Association. Stroke 2010;41:2108-2129.

31. Albrecht JS, Liu X, Baumgarten $\mathrm{M}$, Langenberg $\mathrm{P}$, Rattinger GB, Smith GS, Gambert SR, Gottlieb SS, Zuckerman IH. Benefits and risks of anticoagulation resumption following traumatic brain injury. JAMA Intern Med 2014; 174:1244-1251.

32. McGrath ER, Kapral MK, Fang J, Eikelboom JW, ó Conghaile A, Canavan M, O'Donnell MJ, Investigators of the Registry of the Canadian Stroke Network. Investigators of the Registry of the Canadian Stroke Network which risk factors are more associated with ischemic stroke than intracerebral hemorrhage in patients with atrial fibrillation? Stroke 2012;43:2048-2054.

33. Nielsen PB, Larsen TB, Skjøth F, Overvad TF, Lip GYH. Stroke and thromboembolic event rates in atrial fibrillation according to different guideline treatment thresholds: a nationwide cohort study. Sci Rep 2016; 6 .

34. Lip GYH, Nielsen PB. Should patients with atrial fibrillation and 1 stroke risk factor (CHA2DS2-VASc score 1 in men, 2 in women) be anticoagulated? yes: even 1 stroke risk factor confers a real risk of stroke. Circulation 2016;133:1498-1503.

35. Charidimou A, Wilson D, Shakeshaft C, Ambler G, White M, Cohen H, Yousry T, Al-Shahi Salman R, Lip G, Houlden H, Jäger HR, Brown MM, Werring DJ. The Clinical Relevance of Microbleeds in Stroke study (CROMIS-2): rationale, design, and methods. Int J Stroke 2015;10:155-161.

36. Al-Shahi Salman R, Bell S. The contemporary conundrum of antithrombotic drugs after intracerebral haemorrhage. ACNR 2015; 15:12-15.

37. Nieuwenhuizen VKM, van der Worp HB, Algra A, Kappelle LJ, Rinkel GJ, van Gelder IC, Schutgens RE, Klijn CJ, APACHE-AF Investigators.. Apixaban versus 
antiplatelet drugs or no antithrombotic drugs after anticoagulation-associated intracerebral haemorrhage in patients with atrial fibrillation (APACHE-AF): study protocol for a randomised controlled trial. Trials 2015;16:393.

38. Glynn RJ, Knight EL, Levin R, Avorn J. Paradoxical relations of drug treatment with mortality in older persons. Epidemiology. 2001;12:682-689.

39. Lovelock CE, Cordonnier C, Naka H, Al-Shahi Salman R, Sudlow CL, Edinburgh Stroke Study Group, Sorimachi T, Werring DJ, Gregoire SM, Imaizumi T, Lee SH, Briley D, Rothwell PM. Antithrombotic drug use, cerebral microbleeds, and intracerebral hemorrhage: a systematic review of published and unpublished studies. Stroke 2010;41:1222-1228.
40. Yates PA, Villemagne VL, Ellis KA, Desmond PM, Masters CL, Rowe CC. Cerebral microbleeds: a review of clinical, genetic, and neuroimaging associations. Front Neurol 2014;4:205.

\section{${ }^{*}$ Correspondence to}

Xiaoli Min

Yunnan University of Traditional Chinese Medicine

Kunming, Yunnan

China 